\title{
Towards "Green" Smart Materials for Force and Strain Sensors: The Case of Polyaniline
}

Cristina Della Pina, a, Emanuele Zappa ${ }^{2, b}$, Giorgio Busca ${ }^{2, c}$, Pedro Costa ${ }^{3, d}$, Senentxu Lanceros-Mendéz, ${ }^{3, e}$, Annalisa Sironi ${ }^{1, f}$ and Ermelinda Falletta ${ }^{1, g}$

${ }^{1}$ Dipartimento di Chimica, CNR-ISTM, Università degli Studi di Milano, via Golgi, 19, 20133, Milan, Italy

2 Dipartimento di Meccanica, Politecnico di Milano, via La Masa, 1, 20158, Milano, Italy

${ }^{3}$ Centro/Dept. de Física da Universidade do Minho, 4710-058 Braga, Portugal

acristina.dellapina@unimi.it, bemanuele.zappa@polimi.it, cgiorgio.busca@polimi.it, dpedrofrcosta@gmail.com, elanceros@fisica.uniminho.pt, 'syron74@gmail.com, germelinda.falletta@unimi.it

Keywords: polyaniline, green synthesis, piezoresistivity, sensors.

Abstract. Stress/strain sensors constitute a class of devices with a global ever-growing market thanks to their use in many fields of modern life. They are typically constituted by thin metal foils deposited on flexible supports. However, the low inherent resistivity and limited flexibility of their constituents make them inadequate for several applications, such as measuring large movements in robotic systems and biological tissues. As an alternative to the traditional compounds, in the present work we will show the advantages to employ a smart material, polyaniline (PANI), prepared by an innovative environmentally friendly route, for force/strain sensor applications wherein simple processing, environmental friendliness and sensitivity are particularly required.

\section{Introduction}

In the fabrication of ccommercial strain gauges the possibility to substitute metal films, characterized by low resistivity and low flexibility, with light, flexible and cheap materials is increasingly needed. In this contest, conducting organic polymers represent an interesting alternative to traditional materials. Among them, polyaniline (PANI, Fig. 1) is particularly interesting for many aspects strictly related to its chemical-physical characteristics: ease of synthesis, low cost, high environmental stability and unique doping/dedoping process.

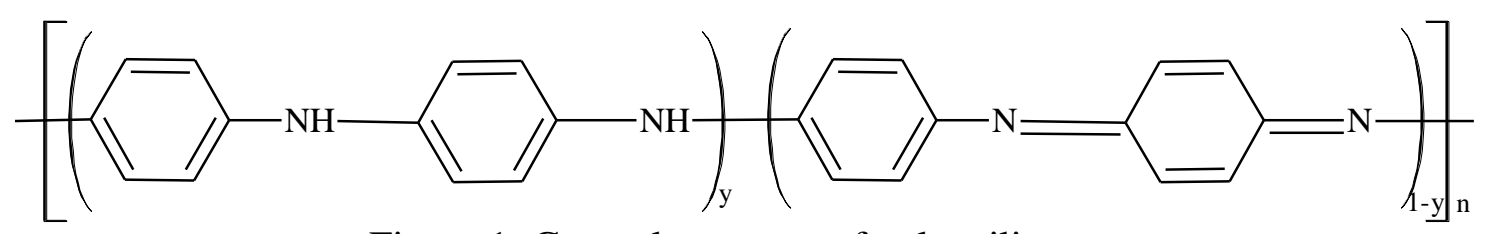

Figure 1: General structure of polyaniline.

It exists in three main forms, classified upon the chain's oxidation grade, ranging from the totally reduced leucoemeraldine $(\mathrm{y}=1)$ to the half-oxidized emeraldine $(\mathrm{y}=0.5)$ as well as the totally oxidized pernigraniline $(\mathrm{y}=0)$.

Only the half-oxidized and half-protonated form, emeraldine salt (ES), exhibits electroconductive properties and for this reason it has received large attention.

Despite that and thatsome investigations recently appeared on piezoresistive effect of PANI composites [1, 2], there are not enough information on the piezoresistive sensing possibilities of pristine polyaniline. Actually, in this regard, only two works were published [3, 4], bringing different results. In fact, on the one hand Lillemose et al. reported negative GF (gauge factor) values of about -5 in 4-point bending experiments, whereas on the other hand the GFs obtained by Lanceros-Méndez and co-workers ranged from 10 to 22. It is important to highlight that all these 
results were obtained using commercial polyaniline (PANIPOL $® \mathrm{~T})[5]$, prepared by a traditional approach, based on aniline monomer polymerization. Even though the aniline chemical polymerization is still the most popular route to prepare PANI in large scale, this pathway entails strong drawbacks strictly related the use of "stoichiometric oxidants", such as ammonium persulfate [6], potassium bichromate [7] and so on, that cause the formation of large amount of polluting and/or carcinogenic co-products, that reduce the polymer purity, restricting its applications. Moreover, polymer produced by this way is characterized by poor tractability that complicates its employment. According to the growing environmental constraints invoking to substitute the traditional polluting synthetic methods with ecofriendly protocols and stimulated by the growing request of innovative smart materials in medical and biomedical fields, we recently addressed our efforts on developing new environmentally friendly synthetic approaches for the conducting organic polymers preparation [8-12]. In this regard, particular attention has been devoted to prepare conductive polyaniline ("green" PANI) with high processability (e. g., solubility in common organic solvents) and purity (e.g., free from benzidine, carcinogenic specie regularly produced by aniline monomer polymerization and metals in high oxidation state).

Herein, we will report the preparation and characterization of "green" PANI and its electromechanical response as pellet [13] and film.

\section{Experimental Procedure}

All chemicals were purchased by Sigma Aldrich and used as received without further purification.

\subsection{Synthesis of "Green" Polyaniline}

"Green" polyaniline was prepared by chemical oxidative polymerization of $\mathrm{N}$-(4aminophenyl)aniline (aniline dimer, $\mathrm{AD}$ ) in the presence of $\mathrm{H}_{2} \mathrm{O}_{2}$ as oxidant and $\mathrm{Cu}^{2+}$ as catalyst [10].

$2 \mathrm{~g}$ of $\mathrm{AD}$ were dissolved in $27 \mathrm{~mL}$ of $\mathrm{HCl} 0.4 \mathrm{M}(\mathrm{AD} / \mathrm{HCl}=1$, molar ratio $)$ at room temperature. Then, $5.60 \mathrm{~mL}$ of $\mathrm{H}_{2} \mathrm{O}_{2} 30 \%\left(\mathrm{H}_{2} \mathrm{O}_{2} / \mathrm{AD}=5\right.$, molar ratio) were added into the green solution, immediately followed by $0.54 \mathrm{~mL}$ of $\mathrm{Cu}^{2+} 0.02 \mathrm{M}$ aqueous solution $\left(\mathrm{AD} / \mathrm{Cu}^{2+}=1000\right.$, molar ratio), prepared dissolving the appropriate amount of $\mathrm{CuCl}_{2} \cdot 2 \mathrm{H}_{2} \mathrm{O}$ in deionized water. An insoluble green powder was collected after 24 hours by filtration. This material was washed several times by water and acetone in order to remove oligomers and dried under air. $1 \mathrm{~g}$ of this product, obtained with a yield of $73 \%$ and spectroscopically identified as emeraldine salt, was dedoped (deprotonated) by stirring in $20 \mathrm{~mL}$ of $\mathrm{NH}_{4} \mathrm{OH} 0.5 \mathrm{M}$ at room temperature. After 24 hours, a dark blue product (emeraldine base) was filtered, washed several times with water until the mother liquors became neutral and dried under air.

\section{2. $\mathrm{PANI} / \mathrm{H}_{2} \mathrm{SO}_{4}$ Pellet Preparation}

$500 \mathrm{mg}$ of emeradine base, prepared as described above (section 2.1.), were redoped (reprotonated) by $9 \mathrm{~mL}$ of $\mathrm{H}_{2} \mathrm{SO}_{4} 0.3 \mathrm{M}\left(\mathrm{AD} / \mathrm{H}_{2} \mathrm{SO}_{4}=1\right.$, molar ratio), thus obtaining PANI/H$/ \mathrm{SO}_{4}$. After 6 hours, the dark green product was filtered, washed several times with water and dried under air. $\mathrm{H}_{2} \mathrm{SO}_{4}$ was chosen as the doping agent for its chemical and thermal stability.

Two pellets having diameter of $13 \mathrm{~mm}$ and thickness of $1 \mathrm{~mm}$ were prepared pressing $200 \mathrm{mg}$ of $\mathrm{PANI} / \mathrm{H}_{2} \mathrm{SO}_{4}$ for 30 minutes at $100 \mathrm{kN}$ using an Atlas Manual Hydraulic Press.

\subsection{PANI/CSA Film Preparation}

$500 \mathrm{mg}$ of emeradine base, prepared as described above (section 2.1.), were dispersed in $20 \mathrm{~mL}$ of $\mathrm{CHCl}_{3}$. Then, $631 \mathrm{mg}$ of camphorsulfonic acid (CSA, $\mathrm{AD} / \mathrm{CSA}=1$, molar ratio) were added into the solution and stirred at room temperature. After 24 hours, a green solution containing soluble PANI/CSA was separated by the insoluble part by filtration and then evaporated under vacuum, leading to a solid material having a solubility in chloroform of $13 \mathrm{mg} / \mathrm{mL}$. 
$10 \mathrm{~mL}$ of this PANI/CSA solution were deposited by drop casting on polyethylene terephthalate (PET) substrates and solvent was evaporated under air.

\subsection{Samples Characterization}

All materials were characterized by FT-IR and UV-vis spectroscopies and X-ray powder diffraction (XRPD).

For PANI-based pellets uniaxial compression tests were carried out with a MTS alliance RT/100 universal mechanical test machine that allows maximum loads of $100 \mathrm{kN}$ both for tensile and compression tests with a maximum velocity of $508 \mathrm{~mm} / \mathrm{min}$. The axial loads were measured by a load cell MTS 4501058 with $\pm 100 \mathrm{kN}$ measurement range and $0.1 \mathrm{~V} / \mathrm{kN}$ sensitivity, whereas the axial displacements were measured by a deflectometer MTS model $632.06 \mathrm{H}-30$ with $\pm 12.5 \mathrm{~mm}$ measurement range. In order to carry out these tests, $\mathrm{PANI} / \mathrm{H}_{2} \mathrm{SO}_{4}$ samples were sandwiched between two circular copper plates connected to a multimeter and placed between two steel disks (Fig. 2), isolated with respect to the loading machine by means of thin non-conductive films.

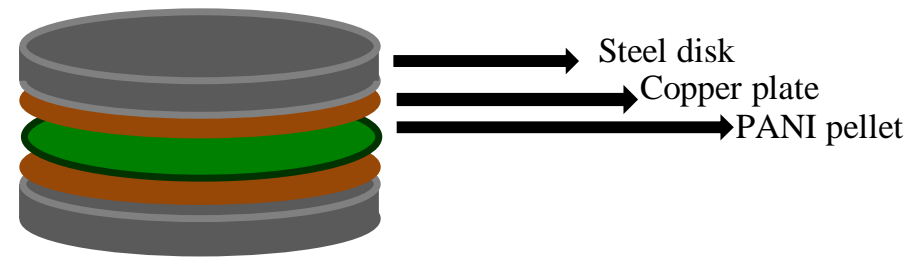

Figure 2: PANI pellet support.

The PANI pellet support ensures on the one hand a homogeneous distribution of loads on the pellet surface and on the other hand the electrical resistance measurement by the connection with the multimeter.

After a first stabilization cycle carried out on the support in the absence of any sample, for each pellet three loading/unloading cycles were performed in a range of $0 \mathrm{kN}-100 \mathrm{kN}$ with a loading step of $10 \mathrm{kN}$.

In the case of PANI/CSA films two parallel rectangular gold electrodes were deposited by magnetron sputtering on one side of the sample and two copper wires were attached to the electrodes to ensure good electrical contact (Fig. 3).

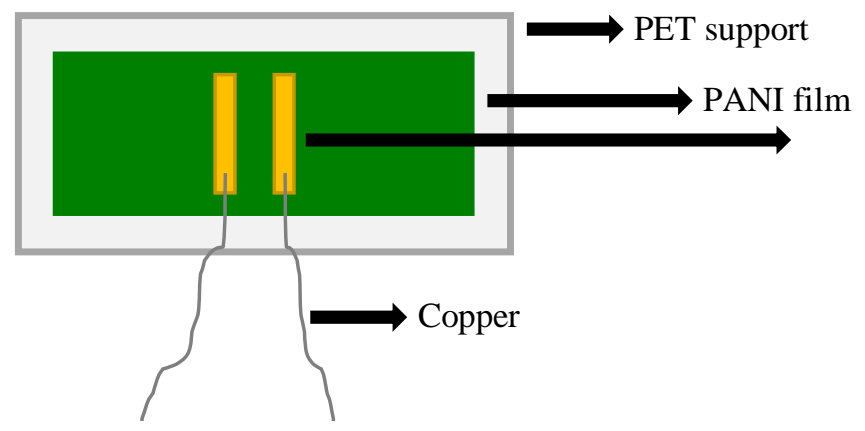

Figure 3: Schematic diagram of PANI/CSA films supported on PET.

PANI/CSA electromechanical properties were investigated by 4-point-bending tests in a ShimadzuAG-IS $500 \mathrm{~N}$ testing instrument at a speed of $2.5 \mathrm{~mm} / \mathrm{min}$ and a maximum vertical ( $\mathrm{z}$ axis) displacement of $2.5 \mathrm{~mm}$ while simultaneously measuring the electrical resistivity variation with a digital multimeter Agilent 34401A.

The electrical conductivity values were estimated indirectly from resistivity ( $\rho$ ) determination from the I-V curves measurements performed in direct current (DC) mode with an applied voltage 
ranging between $\pm 5 \mathrm{~V}$, at room temperature with a Keithley 487 picoammeter/ voltage source. The resistivity was calculated from Equation 1 (Eq. 1):

$$
\rho=\mathrm{R} \frac{A}{\ell} \quad \text { Eq. } 1
$$

where $\mathrm{R}, \mathrm{A}$ and $\ell$ are the electrical resistance $(\mathrm{Ohm})$, the cross-sectional area $\left(\mathrm{m}^{2}\right)$ and the length (m) of the piece of material respectively.

The morphological characterization of the films were performed by scanning electron microscopy, after gold sputtering by magnetron sputtering with a SC502 sputter coater, using a Leica Cambridge set up with an accelerating voltage of $10 \mathrm{kV}$.

\section{Results and Discussion}

\section{1. "Green" Polyaniline Advantages}

The most common polyaniline synthesis is based on the radical oxidative polymerization of aniline, according to the reaction mechanism schematized below (Scheme 1) [14-16].

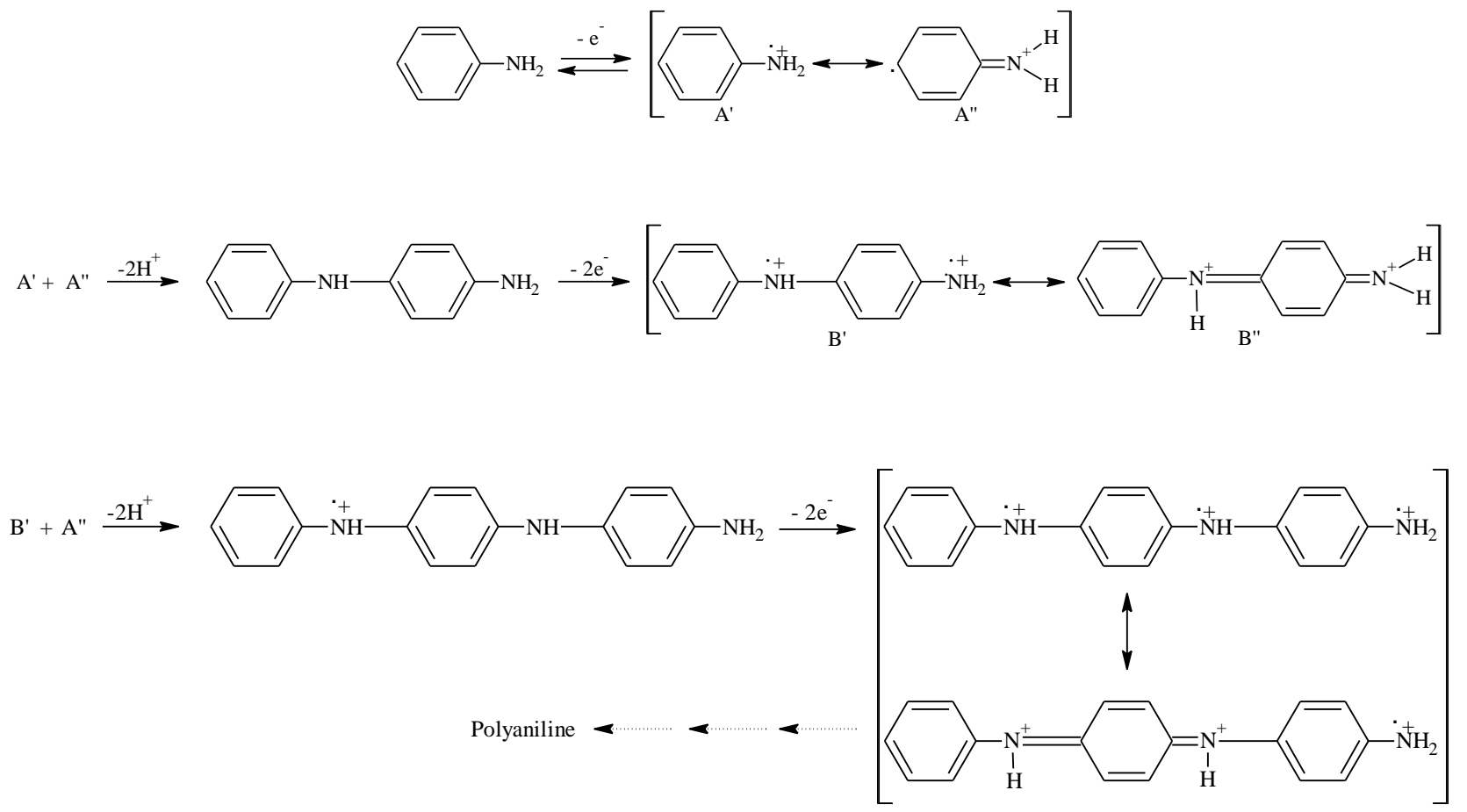

Scheme 1: Mechanism of aniline oxidative polymerization.

As reported by Wei et al. [14, 15], the thermodynamic limitation in the aniline oxidative polymerization consists in the aniline monomer oxidation to form dimeric species [ $N$-(4aminophenyl)aniline, trans-azobenzene and benzidine] (Fig. 4).
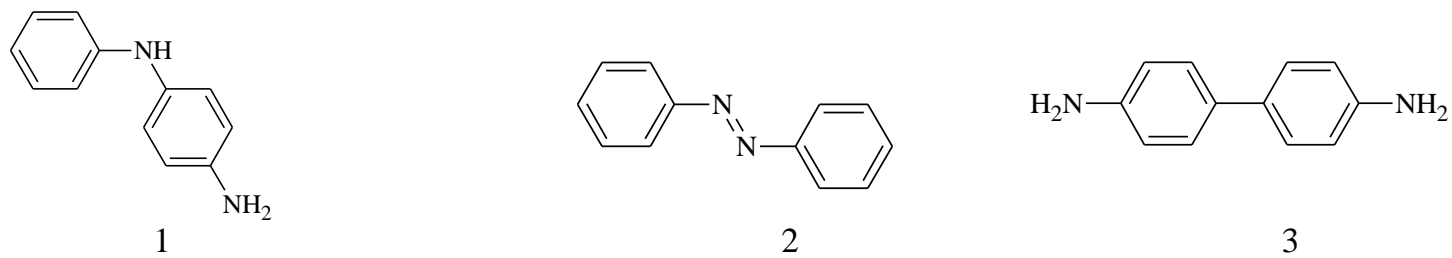

Figure 4: 1) $N$-(4-aminophenyl)aniline, 2) trans-azobenzene and 3) benzidine. 
Once dimers are produced in the reaction mixture, they react immediately leading to first oligomers and then polymers.

If on the one hand the trans-azobenzene formation can affect the structure and purity of the final polymer influencing its performances, on the other hand the benzidine production is risky for its toxic and carcinogenic properties [17], limiting the application potential of PANI produced by this way, in particular in the medical and biomedical sectors.

On the contrary, the oxidative polymerization of $N$-(4-aminophenyl)aniline does not result in benzidine formation [18]. However, this approach leads to a kind of polyaniline characterized by relatively short chains and low molecular weights [19] that increase the polymer processability (e.g., solubility in common organic solvents [20]) but at the same time reduces its conductivity [10, 19].

Moreover, the use of $\mathrm{N}$-(4-aminophenyl)aniline as the reagent, instead of the aniline monomer, overcomes the thermodynamic limitation of the dimer formation discussed above, allowing to carry out the reaction by employing milder and environmentally friendly oxidizing agents, such as molecular oxygen and hydrogen peroxide in the presence of specific catalysts, producing only water as the co-product, in line with the growing environmental constraints invoking more eco-sustainable approaches [10-12].

In this regard, we demonstrated that copper as metal and salts [10] but also iron salts [20] and magnetic nanoparticles $\left(\mathrm{Fe}_{3} \mathrm{O}_{4}\right)$ [12] are good catalysts for the $\mathrm{N}$-(4-aminophenyl)aniline oxidative polymerization.

\subsection{Spectroscopic Characterization}

The FT-IR and UV-vis spectra (Fig. 5A, C and D) show that materials obtained after both procedures were obtained in the form of conductive emeraldine salt.
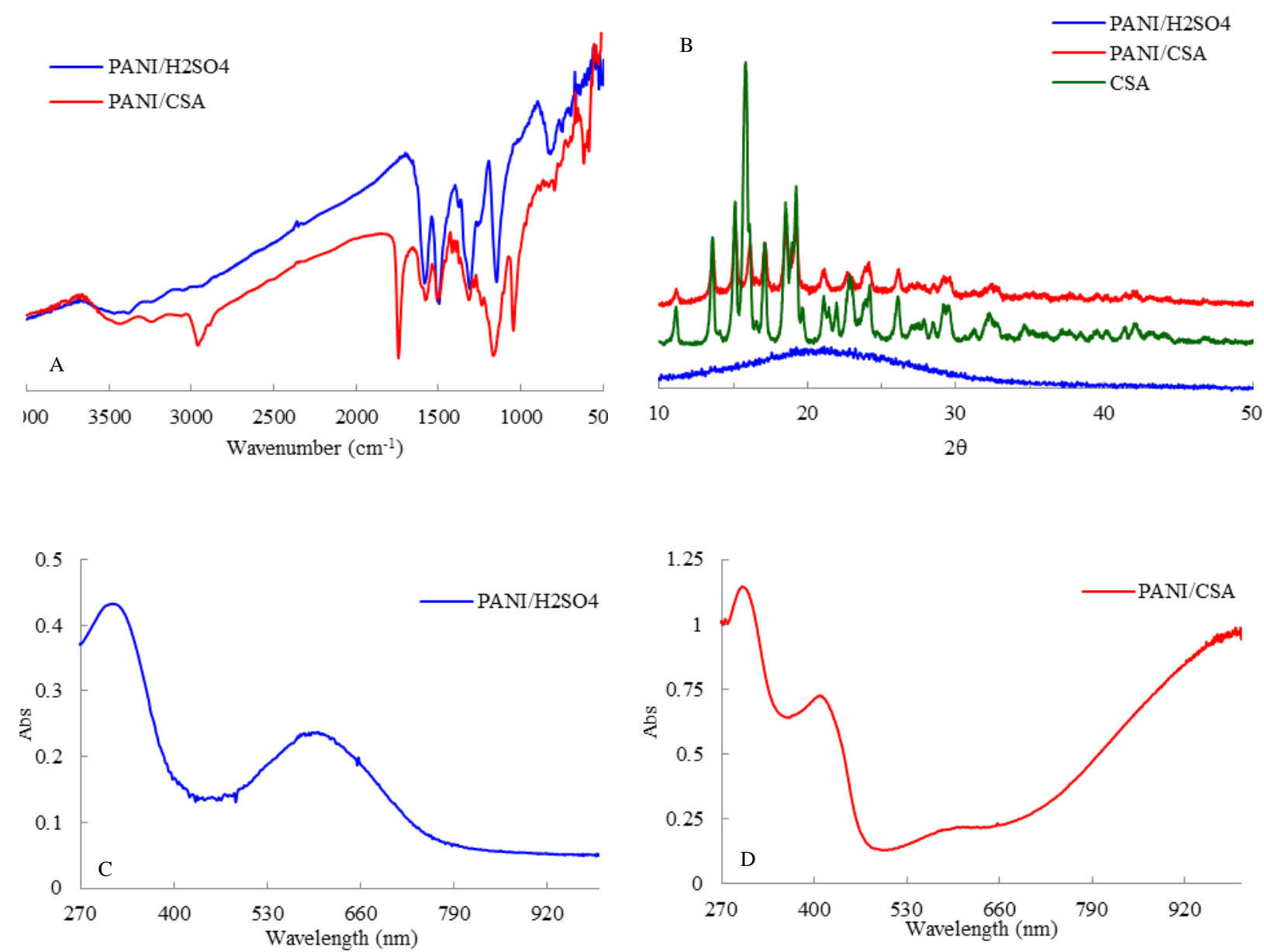

Figure 5: A) FT-IR spectra and B) XRPD patterns of both $\mathrm{PANI} / \mathrm{H}_{2} \mathrm{SO}_{4}$ and $\mathrm{PANI} / \mathrm{CSA}$, C) UVvis spetrum of $\mathrm{PANI} / \mathrm{H}_{2} \mathrm{SO}_{4}$ in dimethylformamide, D) $\mathrm{UV}$-vis spectrum of $\mathrm{PANI} / \mathrm{CSA}$ in chloroform. 
More in detail, FT-IR spectra (Fig. 5A) shows the typical $\mathrm{C}=\mathrm{C}$ stretching band of the quinoid $(\mathrm{N}=\mathrm{Q}=\mathrm{N})$ and benzenoid rings $(\mathrm{N}-\mathrm{B}-\mathrm{N})$ at $1570 \mathrm{~cm}^{-1}$ and $1498 \mathrm{~cm}^{-1}$, respectively. The bands at $1311 \mathrm{~cm}^{-1}$ and $1246 \mathrm{~cm}^{-1}$ are assigned to the $\mathrm{C}-\mathrm{N}$ and $\mathrm{C}=\mathrm{N}$ stretching modes respectively, whereas those at $1027 \mathrm{~cm}^{-1}$ and $889 \mathrm{~cm}^{-1}$ are strictly related to the in-plane and out-of-plane bending of C-N. Finally, the deformation vibration modes of the aromatic rings are responsible for the bands at 754 $\mathrm{cm}^{-1}$ and $692 \mathrm{~cm}^{-1}$ and the band at $573 \mathrm{~cm}^{-1}$ is typical of a 1,4 di-substituted benzene [21]. In the FT-IR spectrum of PANI/CSA the typical band of $\mathrm{C}=\mathrm{O}$, due to the dopant, is evident at $1730 \mathrm{~cm}^{-1}$, such as the bands at $1160 \mathrm{~cm}^{-1}, 752 \mathrm{~cm}^{-1}$ and $619 \mathrm{~cm}^{-1}$ that are attributed to $\mathrm{S}=\mathrm{O}, \mathrm{C}-\mathrm{S}$ and $\mathrm{S}-\mathrm{O}$ respectively. The bands of the $\mathrm{S}=\mathrm{O}$ bending vibration modes are evident at 1350, 1050 and 1000 $\mathrm{cm}^{-1}$, whereas those between 3000 and $2000 \mathrm{~cm}^{-1}$ are typical of C-H stretching modes.

Concerning the UV-vis spectra, owing to the different solubility of PANI, related to the different doping agents employed, they were recorded in different solvents (dimethylformamide for $\mathrm{PANI} / \mathrm{H}_{2} \mathrm{SO}_{4}$ and chloroform for PANI/CSA), which is reflected in the results. In particular, solvents as dimethylformamide and 2-pyrrolidinane cause dedoping (deprotonation) phenomena [22].

In fact, Fig. 5C is the typical UV-vis spectrum of polyaniline in emeradine base form [23], wherein the bands at 311 and $603 \mathrm{~nm}$ are respectively related to the $\pi-\pi^{*}$ transition of the benzenoid rings and the transition from a localized benzenoid highest occupied molecular orbital (HOMO) to a quinoid lowest unoccupied molecular orbital (LUMO), that is a benzenoid to quinoid excitonic transition.

On the contrary, the UV-vis spectrum of PANI/CSA (Fig. 5D) shows the characteristic bands of PANI in form of conducting emeraldine salt. Compared to the spectrum of emeradine base (Fig. 5C), the band at $603 \mathrm{~nm}$ is less evident and two new bands appear at 402 and $990 \mathrm{~nm}$, assigned to the polarons and bipolarons formation respectively. Moreover, the latter band, typically observed at lower wavelengths (790-856 nm) [24], is shifted in the visible region. This bathochromic effect can be attributed to many aspects: materials nanostructured form, $\pi$ conjugation extension [25], but also to switch from coil-like to expanded conformation of the polymeric chains [26].

Finally, X-ray powder diffraction spectra emphasizes the different degree of crystallinity of both materials.

Low PANI crystallinity can be related to different factors: conditions of synthesis, kind and amount of acid used as doping agent, molecular weight and random orientation of polymeric chains [27-30]. As shown in Fig. 5B, the XRPD pattern of PANI/ $\mathrm{H}_{2} \mathrm{SO}_{4}$ is characteristic of an amorphous material with a broad band at $2 \theta \approx 20$, typical of PANI [31]. On the contrary, PANI/CSA sample exhibits higher crystallinity strictly related to the presence of a crystalline dopant. However, also in this case the broad band of PANI is evident.

\subsection{Electrical conductivity}

As summarized in Table 1, the electrical conductivity of $\mathrm{PANI} / \mathrm{H}_{2} \mathrm{SO}_{4}$ is about 45 times higher than the one of PANI/CSA.

Table 1: Values of d. c. conductivity for $\mathrm{PANI} / \mathrm{H}_{2} \mathrm{SO}_{4}$ and PANI/CSA.

\begin{tabular}{|c|c|}
\hline Sample & Conductivity $(\mathrm{S} / \mathrm{cm})$ \\
\hline $\mathrm{PANI} / \mathrm{H}_{2} \mathrm{SO}_{4}$ & $7.62 \cdot 10^{-6}$ \\
\hline PANI/CSA & $1.67 \cdot 10^{-7}$ \\
\hline
\end{tabular}

PANI conductivity is affected by many parameters, such as amount and kind of dopant [32, 33], humidity [34, 35], degree of crystallinity [35] and molecular weight [36-40]. These latter parameters are the most important and some of them can be tailored during the reaction, properly 
choosing the reaction conditions (i.e. medium, temperature, kind of oxidant and acid), or after the reaction by specific treatments (i.e. change of acid dopant, thermal treatment and so on) [41, 42].

Concerning the type of dopant employed, a key role is played by its dimensions.

Regarding this aspect, it is to notice that the polyaniline conductivity, but more in general the conductivity of all conducting organic polymers, is the sum of two contributions: the ability of the charge carriers to move along the polymer backbone by an intra-chain conduction mechanism (Fig. 6A) and their ability to hop between neighbouring polymeric chains by an inter-chain conduction mechanism (Fig. 6B). This second contribution becomes particularly important when the material is subjected to a deformation.

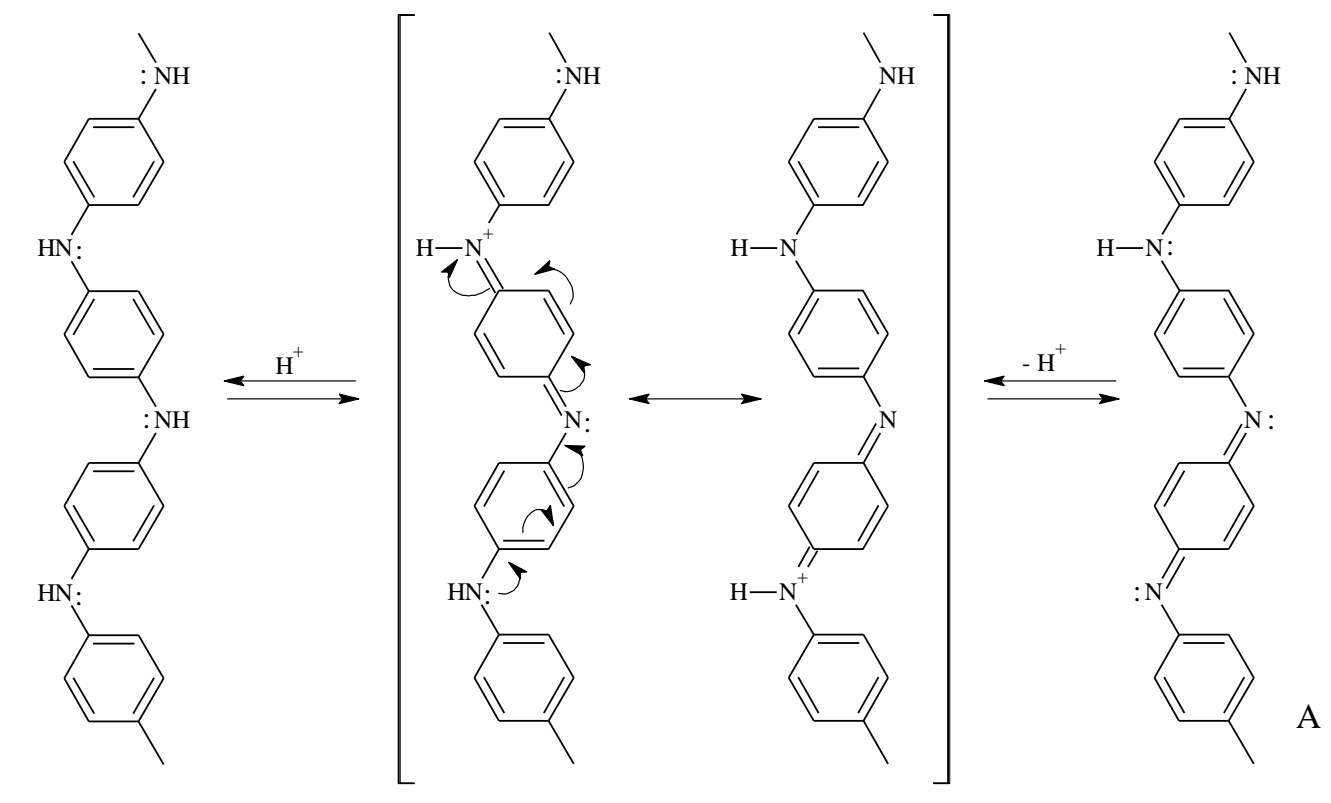<smiles>CN=C1C=CC(=Nc2ccc(Nc3ccc(Nc4ccc(C)cc4)cc3)cc2)C=C1</smiles><smiles></smiles><smiles>CNc1ccc(Nc2ccc([NH+]=C3C=CC(=[NH+]c4ccc(C)cc4)C=C3)cc2)cc1</smiles><smiles>CNc1ccc(Nc2ccc(N=C3C=CC(=[NH+]c4ccc(C)cc4)C=C3)cc2)cc1</smiles><smiles></smiles>

Figure 6: A) Intra-chain and B) inter-chain conduction mechanism of polyaniline.

The inter-chain distance (or spacing) is strongly dependent on the dopant size, kind of polymeric backbone-dopant interactions (typically hydrogen bonds) and structural rigidity [43]. 
In our case the steric hindrance of camphorsulfonic acid is much greater than that of sulphuric acid, limiting the carrier movement between chains and, therefore, decreasing the conductive behaviour of the polymer.

Moreover, as reported in sections 2.2. and 2.3., the pellets were prepared by pressing the overall $\mathrm{PANI} / \mathrm{H}_{2} \mathrm{SO}_{4}$ sample, whereas for the films preparation only the portion of PANI/CSA sample soluble in $\mathrm{CH}_{3} \mathrm{Cl}$ was employed. If on the one hand the use of a big organic acid increases PANI solubility in common organic solvents [44], on the other hand only short polymeric chains are solubilized. For this reason, even though samples were not characterized in terms of molecular weights, it is possible to conclude that PANI/CSA sample consists on polymeric chains shorter than those of PANI/ $\mathrm{H}_{2} \mathrm{SO}_{4}$ sample.

\subsection{Electromechanical Response}

\subsubsection{PANI/ $/ \mathrm{H}_{2} \mathrm{SO}_{4}$ Pellet}

Recently, it was demonstrated that $\mathrm{PANI} / \mathrm{H}_{2} \mathrm{SO}_{4}$ pellets exhibit interesting electromechanical response under compression-expansion conditions [13].

After an initial mechanical material stabilization during the first force-compression cycle, the subsequent ones are almost linear and hysteresis-free (Fig. 7A), even though two different regimes can be recognized: below and over $\sim 0.1 \mathrm{~mm}$.
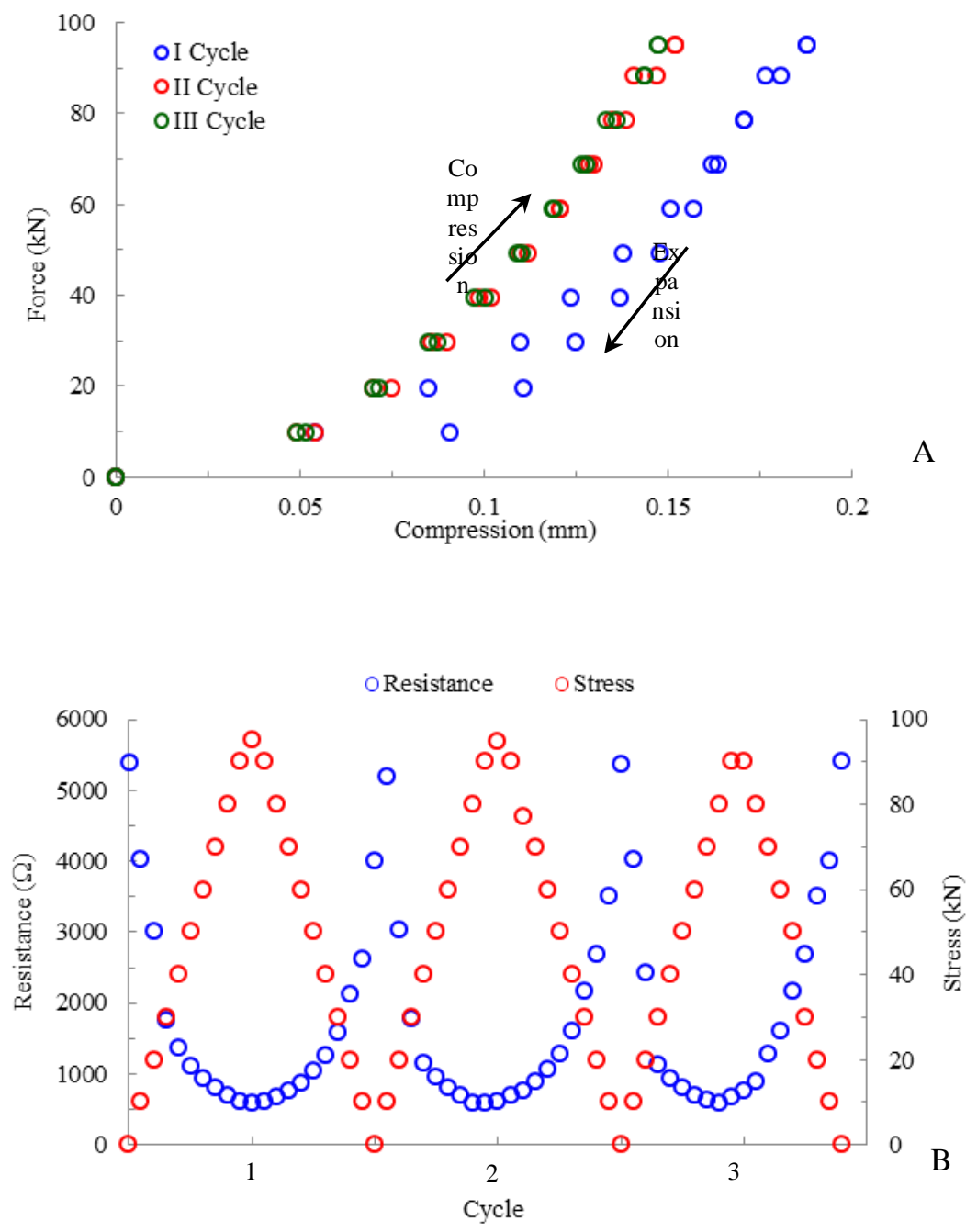


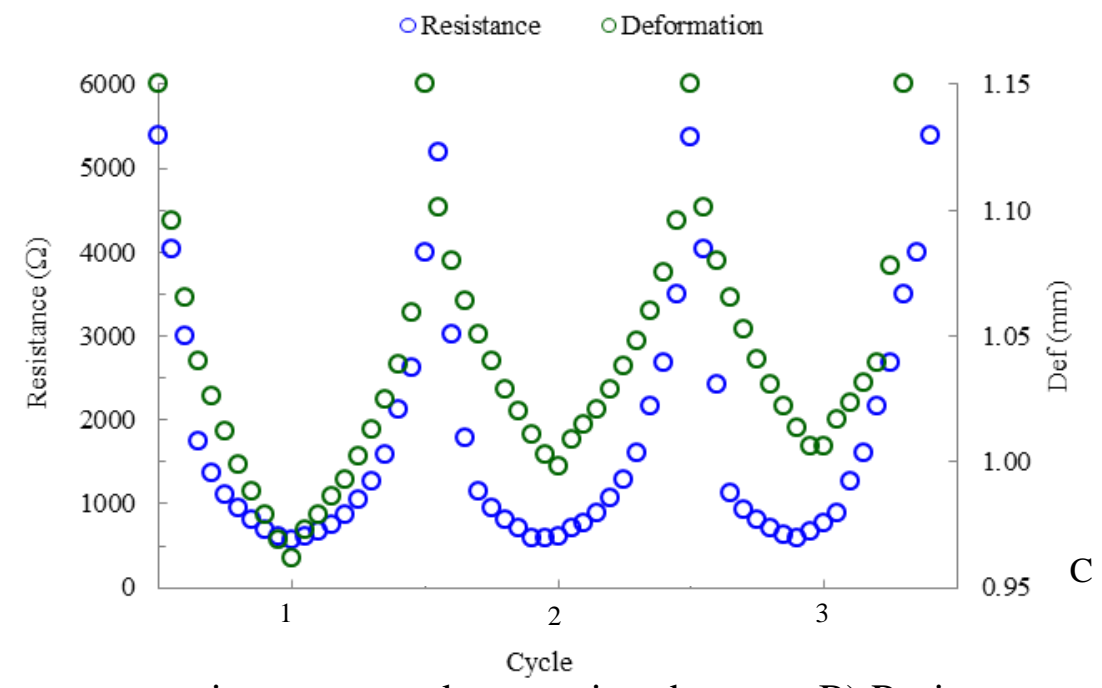

Figure 7: A) Force vs compression curves and comparison between B) Resistance and Force variation and C) Resistance and Deformation variation under compression/expansion cycles.

These two regimes can be attributed to the presence of voids among the polymeric chains, which can be reduced by the application of high loads.

The electrical resistance of the sample decreases upon loading and increases upon unloading reversibly and almost linearly. A resistance variation of about $87 \%$ is observed in the range of 0 $100 \mathrm{kN}$ (Fig. 7B), corresponding to a deformation range of 0-17\% (Fig. 7C).

According to the linear regression $(\mathrm{Y}=\mathrm{kX})$, the fractional change in electrical resistance $\left(\Delta \mathrm{R} / \mathrm{R}_{0}\right)$ plotted as a function of the deformation $\left(\Delta \mathrm{l} / \mathrm{l}_{0}\right)$ (Fig. 8) gives information on the gauge factor value (GF) of this material.

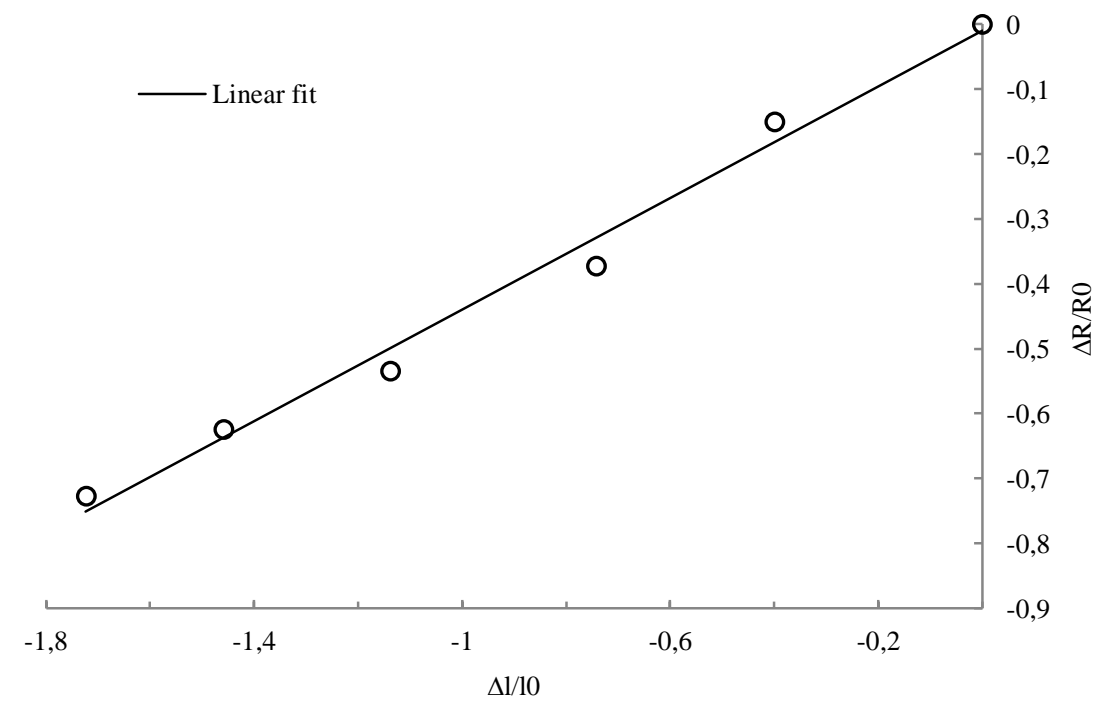

Figure 8: Fractional change in electrical resistance as a function of the strain for the $\mathrm{PANI} / \mathrm{H}_{2} \mathrm{SO}_{4}$ pellets.

The GF value of the $\mathrm{PANI} / \mathrm{H}_{2} \mathrm{SO}_{4}$ pellets is $<1$, too low for practical applications. As reported in Eq. 1, the resistance variation is related to the contribution of two factors: a geometrical effect, due to dimensional changes $(1 / S)$, and an intrinsic contribution, resulting from variations in resistivity $(\rho)$, characteristic of each material. Commercial piezoresistors, whose change in resistance is only related to geometrical factors (e. g., metals) [45], are characterized by low GF values, typical 1-2. 
In the case of PANI-based material, the contribution of the inter-chain conduction mechanism to the overall conductivity should have a positive effect on the resistivity variation of the polymer.

However, the results are not in line with the expectations.

The low GF can be correlated to the low degree of crystallinity of the material. In fact, this latter indicates a random orientation of the polymeric chains in the pellet that can reduce or even suppress the contribution of inter-chain mechanism to the overall conductivity of the sample and leaves only the effect of the geometrical deformation.

In this context, the use of a dopant with high steric hindrance and the possibility to process the polymer as films should emphasize the piezoresistivity of the material. For this purpose camphorsulfonic acid was chosen as doping agent.

\subsubsection{PANI/CSA Film}

The mechanical behaviour of PANI/CSA film was investigated in stress-strain tests for four cycles for a maximum deformation value of $2.5 \mathrm{~mm}$ (Fig. 9A).
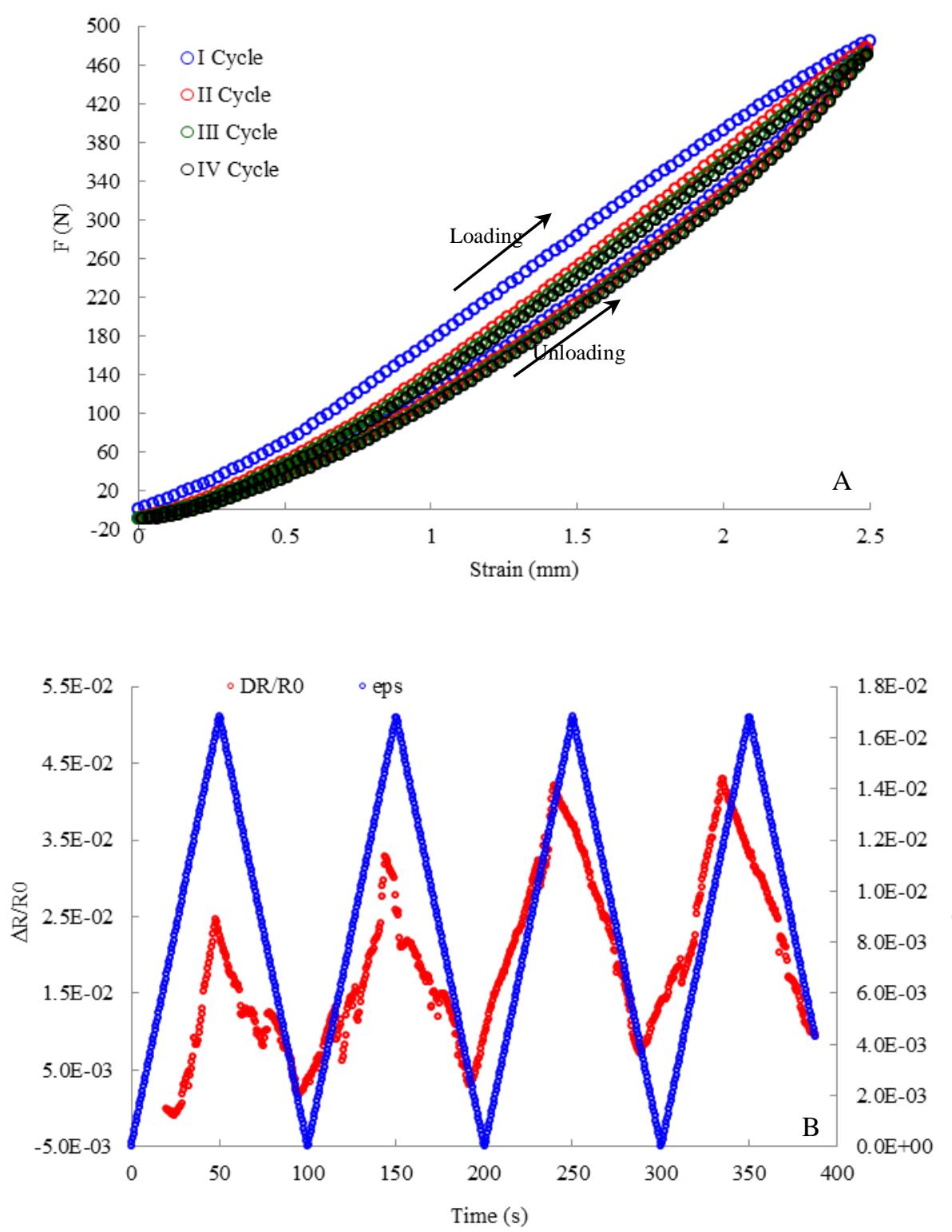

Figure 9: A) Stress-strain curves and B) cyclic piezoresistive response as a function of time for PANI/CSA. 
It is observed that during the first cycle the mechanical hysteresis is particularly evident and increases with increasing deformation. However, it becomes less evident with increasing the number of cycles.

Also in this case, it is possible to recognize two regimes: below and above $\sim 0.6 \mathrm{~mm}$. The first zone shows a nonlinear and almost hysteresis free trend, whereas in the second region a more linear profile characterized by larger hysteresis appears.

In order to explain the presence of two regimes, it is possible to hypothesize two different types of polymer reconfigurations: a morphological modification at low loads and a molecular one at higher loads.

Figure 9B shows that electrical resistance changes almost linearly and reversibly with the applied strain, even though it exhibits a growing trend, probably due to a mechanical instability of the material.

The GF values (Fig. 10B) were evaluated by the slope of the linear fit between $\Delta R / R_{0}$ and $\varepsilon$ (Fig. 10A).
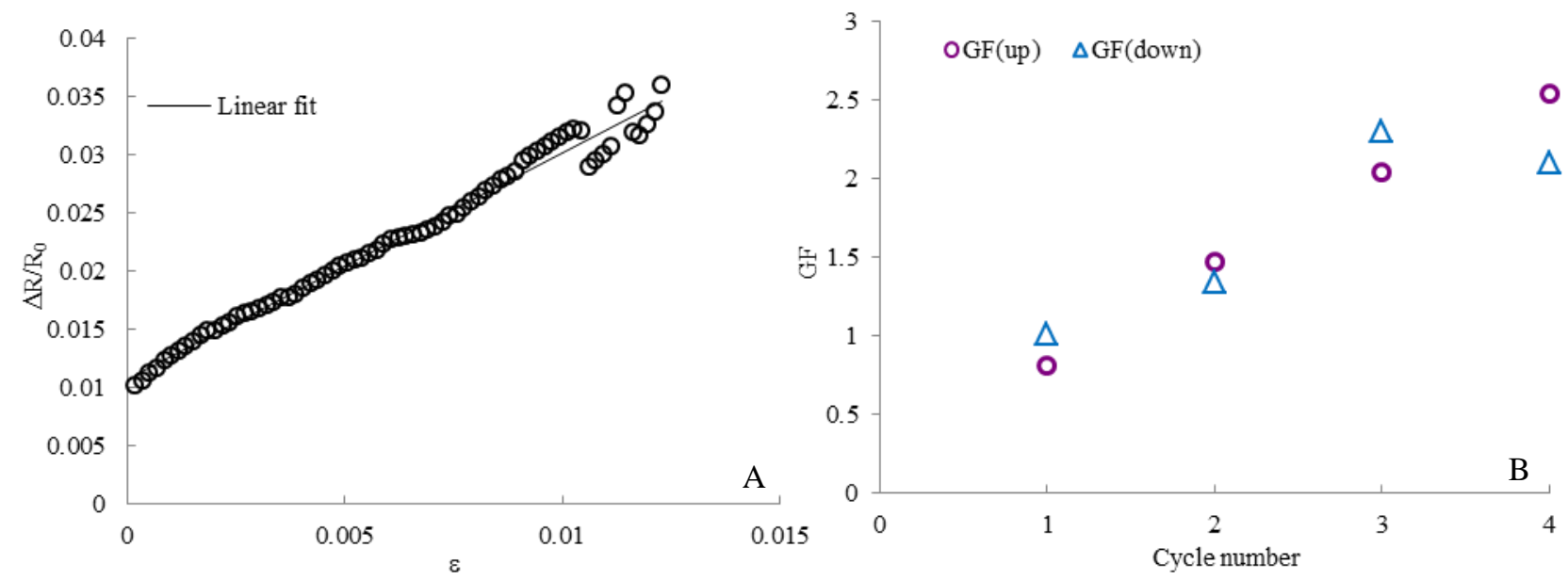

Figure 10: A) Fractional change in electrical resistance as a function of the strain and B) GF variation with the number of cycles for PANI/CSA film.

It is to notice that GFs values are in agreement with those those of the $\mathrm{PANI} / \mathrm{H}_{2} \mathrm{SO}_{4}$ pellet. However, they increase linearly with increasing the number of cycles, suggesting a mechanical instability of the material, according to the results obtained by in stress-strain tests (Fig. 9A).

These results can be attributed to the irregular morphology and high porosity of the material, as confirmed by SEM (Fig. 10).

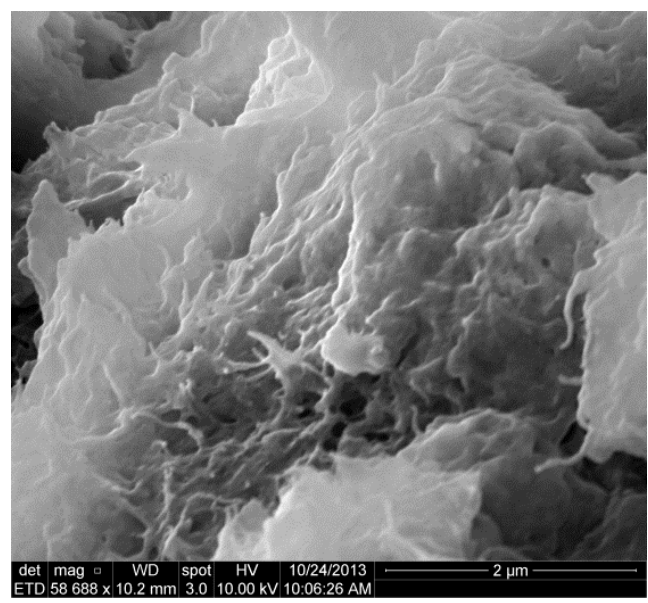


Figure 10: SEM image of PANI/CSA film.

Further investigations are in progress to improve the polymer performance. In particular, a mechanical stabilization after a higher number of cycles along with a proper thermal treatment should overcome these limitations, leading to a more stable material with higher piezoresistive properties.

\section{Acknowledgements}

This work was supported by FEDER through the COMPETE Program and by the Portuguese Foundation for Science and Technology (FCT) in the framework of the Strategic Project PESTC/FIS/UI607/2011 and the project Matepro -Optimizing Materials and Processes", ref. NORTE-070124-FEDER-000037", co-funded by the "Programa Operacional Regional do Norte" (ON.2 - O Novo Norte), under the "Quadro de Referência Estratégico Nacional" (QREN), through the "Fundo Europeu de Desenvolvimento Regional" (FEDER). The authors also thank FCT for financial support under project PTDC/CTM-NAN/112574/2009. The authors also thank the COST Actions MP1003 (European Scientific Network for Artificial Muscles, ESNAM) and MP0902 (Composites of Inorganic Nanotubes and Polymers, COINAPO).

\section{References}

[1] T. del Castillo-Castro, M.M. Castillo-Ortega, J.C. Encinas, P.J. Herrera Franco and H.J. Carrillo-Escalante: J. Mater. Sci., 47 (2012), p. 1794

[2] S. Saïdi, M. Bouzitoun, A. Mannaî, F. Gmati, H. Derouiche and A.B. Mohamed: J. Phys. D: Appl. PHYS. 46 (2013) p. 355101

[3] M. Lillemose, M. Spieser, N.O. Christiansen, A. Christiansen and A. Boisen: Microelectron. Eng. 85 (2008) p. 969

[4] J. Nunes Pereira, P. Vieira, A. Ferreira, A.J. Paleo, J G. Rocha and S. Lanceros-Méndez: J. Polym. Res. 19 (2012) p. 9815

[5] http://www.scmchem.com/eWebEditor/UploadFile/2006711164022504.pdf

[6] A.G. MacDiarmid, J.C. Chiang, M. Halpern, W.S. Huang, S.L. Mu, N.L.D. Somasiri, W.Wu and S.I. Yaniger: Mol. Cryst. Liq. Cryst. 121 (1985) p. 173

[7] G.G. Wallace, G.M. Spinks, L.A.P. Kane-Maguire and P.R. Teasdale in: Conductive Electroactive Polymers: Intelligent Polymer Systems (CRC Press, London, 2009)

[8] Z. Chen, C. Della Pina, E. Falletta, M. Lo Faro, M. Pasta, M. Rossi and N. Santo: J. Catal. 259 (2008) p. 1

[9] C. Della Pina, E. Falletta, M. Lo Faro, M. Pasta and M. Rossi: Gold Bull. 42-1 (2009) p. 27

[10] Z. Chen, C. Della Pina, E. Falletta and M. Rossi: J. Catal. 267 (2009) p. 93

[11] C. Della Pina, E. Falletta and M. Rossi: Cat. Today 160 (2011) p. 11

[12] C. Della Pina, M. Rossi, A.M. Ferretti, A. Ponti, M. Lo Faro and E. Falletta: Synth. Met. 162 (2012) p. 2250

[13] C. Della Pina, E. Zappa, G. Busca, A. Sironi and E. Falletta: Sensor. Actuat. B-Chem (2014) in press 
[14] Y. Wei, G.-W. Jang, Ch.-Ch. Chan, K.F. Hsuen, R. Hariharan, S.A, Patel and C.K. Whitecar: J. Phys. Chem. 94 (1990) p. 7716

[15] Y. Wei, X. Tang, Y. Sun and W.W. Focke: J. Polym. Sci. 27 (1989) p. 207

[16] Y. Wie, R. Hariharan and S.A, Patel: Macromolecules 23 (1990) p. 758

[17] M. H. -C. Chen, L. -C. Hsu, J. -L. Wu, C. -W. Yeh, J. -N. Tsai, Y. -C. Hseu and L. -S. Hsu: Environ. Toxic. (2013) p. 1-9

[18] E. M. Geniès, J. F. Penneau, M. Lapkowski and A. Boyle: J. Electroanal. Chem. 269 (1989) p. $63-75$

[19] A. Kitani, J. Yano, A. Kunai, K. Sasaki: J. Electroanol. Chem. 221 (1987) 69-82

[20] P. Frontera, C. Busacca, S. Trocino, P. Antonucci, M. Lo Faro, E. Falletta, C. Della Pina and M. Rossi: J. Nanosci. Nanotechno. 13 (2013) p. 4744-4751

[21] X. Feng, C. Mao, G. Yang, W. Hou and J. Zhu: Langmuir 22 (2006) p. 4384-4389

[22] Y. H. Geng, Z. C. Sun, J. Li, X. B. Jing, X. H. Wang and F. S. Wang: Polymer 40 (1999) p. 5723-5727

[23] K. Mallick, M. J. Witcomb, A. Dinsmore and M. S. Scurrell: J. Polym. Res. 13 (2006) p. $397-$ 401

[24] J. Stejskal and P. Kratochvil: Synth. Met. 61 (1993) p. 225-231

[25] S. E. Moulton, P. C. Innis, L. A. P. Kane-Maguire, O. Ngamna and G. G. Wallace: Curr. Appl. Phys. 4 (2004) p. 402-406

[26] J. Laska: J. Mol. Stuct. 701 (2004) p. 13-18

[27] M. Pyo and J. -H. Hwang: Synth. Met. 159 (2009) p. 700-704

[28] J. P. Pouget, M. E. Jdzefowiczt, A. J. Epstein, X. Tang and A. G. MacDiarmid: Macromolecules 24 (1991) p. 779-789

[29] K. S. Ryu, S. H. Chang, S. -G. Kang, E. J Oh and C. H. Yo: Bull. Korean Chem. Soc. 20 (1999) p. 333-336

[30] H. K. Chaudhari and D. S. Kelkar: J. Appl. Polym. Sci. 62 (1996) p. 15-18

[31] M. Sivakumar and A. Gedanken: Synth. Met. 148 (2005) 301-306

[32] P. Kiattibutr, L. Tarachiwin, L. Ruangchuay, A. Sirivat and J. Schwank:React. Funct. Polym. 53 (2002) p. 29-37

[33] M. D. Catedral, A. K. G. Tapia, R. V. Sarmago, J. P. Tamayo and E. J. Del Rosario: Science Diliman, 16 (2004) p. 41-46

[34] M. Doriomedoff, F. Hautiere-Cristofini, R. De Surville, M. Jozefowicz, L. T. Yu and R. Buvet: J. Chim. Phys. Phys.- Chim. Biol. 68 (1971) p. 1063

[35] Q. Zhou, J. Wang, Y. Ma, C. Cong and F. Wang: Colloid. Polym. Sci. 285 (2007) p. 405-411

[36] S. Bhadra, N. K. Singha and D. Khastgir: Synth. Met. 56 (2006) p. 1148-1154

[37] S. Bhadra, S. Chattopadhyay, N. K. Singha and D. Khastgir: J. Polym. Sci., Part B: Polym. Phys. 45 (2007) p. 246-259

[38] S. Bhadra, N. K. Singha and D. Khastgir: Polym. Int. 56 (2007) p. 919-927 
[39] S. Bhadra, N. K. Singha and D. Khastgir: J. Appl. Polym. Sci. 104 (2007) p. 1900-1904

[40] S. Bhadra and D. Khastgir: Polym. Degrad. Stab. 92 (2007) p. 1824-1832

[41] J. Joo, Z. Oblakowski, G. Du, J. P. Pouget, E. J. Oh, J. M. Weisinger, Y. Min, A. G. MacDiarmid and A. J. Epstein: Phys. Rev. B 49 (1994) p. 2977-2980

[42] R. Pelster, G. Nimtz and B. Weissling: Phys. Rev. B 49 (1994) p. 12718-12723

[43] J. Joo, H. G. Song, Y. C. Chung, J. S. Baeck, S. K. Jeong, J. S. Suh and E. J. Oh: J. Korean. Phys. Soc. 30 (1997) p. 230-236

[44] Y. Cao, P. Smith and A. J. Heeger: Synth. Met. 48 (1992) p. 91-97

[45] E. Defaÿ, C. Millon, C. Malhaire and D. Barbier: Sensor. Actuat. A-Phys. 33 (1992) 53-56 